\title{
Does aortic crossclamping during the cooling phase affect the early clinical outcome of acute type A aortic dissection?
}

\author{
Franz F. Immer, MD, ${ }^{*}$ Naz Bige Aydin, MD,* Magdalena Lütolf, MD, Eva S. Krähenbühl, MD, Mario Stalder, MD, \\ Lars Englberger, MD, Friedrich S. Eckstein, MD, Jürg Schmidli, MD, and Thierry P. Carrel, MD
}

\begin{abstract}
Objectives: The purpose of this study is to evaluate the effects of crossclamping the ascending aorta in acute type A aortic dissection during the cooling phase for deep hypothermic arrest on early clinical outcome.

Methods: The records of 275 consecutive patients who underwent surgery for acute type A aortic dissection were reviewed. Ten patients have been excluded. Overall, 265 patients who underwent surgery under deep hypothermia and circulatory arrest in the "open technique" were divided retrospectively into two groups: those who underwent surgery with crossclamping of the ascending aorta during the cooling phase at the begin of the procedure (group $1, \mathrm{n}=191 ; 72.1 \%$ ) and those in whom the aorta was not clamped (group $2, \mathrm{n}=74 ; 27.9 \%$ ).
\end{abstract}

Results: Preoperative characteristics were similar in both groups. In group 1, femoral artery cannulation, composite graft repair, and aortic arch replacement were significantly more frequent. In-hospital mortality was $15.2 \%$ in group 1 and $17.6 \%$ in group $2(P=$ not significant). Neurologic deficits were observed in $9.4 \%$ in group 1 and in $10.8 \%$ in group 2 (= not significant). There were no significant differences in clinical outcome between the two groups of patients.

Conclusions: This study demonstrates that both options, aortic crossclamping or noclamping, may be used during the induction of deep hypothermia to repair acute type A aortic dissections with similar early clinical outcome. For the selection of the most appropriate technique, we recommend case by case evaluation, weighing the potential risks and benefits of aortic crossclamping.

Acute aortic dissection type A (AADA) is an emergency situation that requires immediate surgical intervention. ${ }^{1}$ Standard surgical therapy consists of replacing the ascending aorta with resection of the entry tear. The current consensus among the majority of surgical experts is that the distal anastomosis should be performed in an "open fashion" at the level of the proximal arch with deep hypothermic circulatory arrest (DHCA). ${ }^{2-7}$ This allows direct inspection of the aortic arch and may facilitate the confection of the distal anastomosis. Furthermore, this approach favors localization of the intimal tear when it is not visualized in the ascending aorta.

During the cooling period, some surgeons avoid crossclamping the ascending aorta while waiting for the targeted temperature for circulatory arrest to be established, whereas others prefer to crossclamp the ascending aorta during the cooling phase and proceed with the proximal anastomosis first.

There are speculations about the potential risks of cerebral and other malperfusion syndromes when the ascending aorta is crossclamped, but it is still unclear whether this maneuver

From the Department of Cardiovascular Surgery, University Hospital, Berne, Switzerland.

* These authors contributed equally.

Received for publication Feb 26, 2008; revisions received April 28, 2008; accepted for publication May 20, 2008.

Address for reprints: Franz F. Immer, MD, Department of Cardiovascular Surgery, University Hospital, 3010 Berne, Switzerland (E-mail: franzimmer@yahoo.de).

J Thorac Cardiovasc Surg 2008;136:1536-40

$0022-5223 / \$ 34.00$

Copyright $@ 2008$ by The American Association for Thoracic Surgery doi:10.1016/j.jtcvs.2008.05.055 performed before circulatory arrest negatively affects the clinical outcome. Literature addressing this specific question is scarce.

The purpose of this study was to evaluate the effects of crossclamping the ascending aorta in AADA during the cooling period before circulatory arrest on early clinical outcome after repair.

\section{METHODS \\ Patients}

The records of 275 consecutive patients who underwent surgery for AADA during a 10-year period were reviewed with the use of information gathered contemporaneously in our departmental database and supplemented as necessary from patient records. Informed consent was obtained from each patient. The study protocol was approved by the local ethical committee. Seven patients were excluded from the study group because of missing data and 3 patients were excluded because they died in the operating room before the operation could be started.

Patients who underwent aortic repair with DHCA using the "open technique" were divided into two groups according to the operative strategy reported in the patient's chart. Group 1 included $191(72.1 \%)$ patients who underwent surgery with crossclamping of the ascending aorta, and group 2 included those in whom the ascending aorta was not crossclamped during surgery $(n=74 ; 27.9 \%)$. The decision whether or not the aorta would be clamped depended on surgeon's preference and was mainly based on the intraoperative findings. Clamping was much more frequent if aortic root replacement or aortic valve replacement was required and in situations of rupture. Some surgeons had clear preferences whether or not to clamp the aorta. However, overall surgical experience was similar in both groups.

All preoperative, perioperative, and postoperative data were assessed and results are summarized in Tables 1, 2, and 3, respectively.

Malperfusion syndrome was diagnosed when clinical symptoms and/or radiologic evidence were present and defined accordingly to a recent publication. $^{8}$ 


\section{Abbreviations and Acronyms \\ AADA = acute aortic dissection type A \\ $\mathrm{CPB}=$ cardiopulmonary bypass \\ DHCA = deep hypothermic circulatory arrest \\ NS = not significant \\ PRIND = prolonged reversible ischemic neurological deficit \\ TIA $=$ transient ischemic attack \\ TND = temporary neurologic dysfunction \\ RAACP $=$ continuous cerebral perfusion through the right subclavian artery}

Postoperative myocardial infarction was defined as elevation of the MB isoform of creatine kinase over $60 \mathrm{IU} / \mathrm{L}$.

\section{Definitions of Neurologic Complications}

Neurologic examination was performed in all patients in the intensive care unit while awaking or immediately after extubation. A computed tomographic and/or magnetic resonance imaging scan of the brain was performed in all patients, who showed signs or symptoms of neurologic dysfunction. Cerebrovascular incident was defined as a new neurologic deficit compatible with a lesion diagnosed by computed tomographic and/or magnetic resonance imaging scan.

Duration of neurologic symptoms was monitored to subdivide cerebrovascular incidents into transient ischemic attack (TIA) lasting less than 24 hours or prolonged reversible ischemic neurological deficit (PRIND) between 24 and 72 hours versus persistent cerebrovascular accident with neurologic symptoms longer than 72 hours.

Temporary neurologic dysfunction (TND) was defined as a Glasgow Coma Scale value less than 13 . These patients typically exhibit loss of orientation, slurred speech, agitation, and absence of adequate reaction to commands. Glasgow Coma Scale was assessed in the intensive care unit every second hour and at least 3 times daily on the ward. All patients with TND required treatment with psychotropic drugs to control agitation and delirium. More subtle forms of neurologic dysfunction such as minimal disorientation and agitation that did not require sedative medication were not reported as TND in the current study.

\section{Surgical Procedures}

Surgical repair of AADA was performed through a midline sternotomy. During the study period, cardiopulmonary bypass (CPB) was conducted with deep hypothermia after arterial and venous cannulation (Table 2). Maximal temperature gradient during cooling and rewarming was not superior to $10^{\circ} \mathrm{C}$, target tympanic temperature being between $18^{\circ} \mathrm{C}$ and $20^{\circ} \mathrm{C}$. Transesophageal echocardiography was routinely used to detect pathologic blood flow. During the whole study period the cooling and rewarming protocol remained the same. Phenobarbital $(15-20 \mathrm{mg} / \mathrm{kg})$ was administered 2 to 3 minutes before initiation of DHCA.

Modality of cerebral protection was modified in the observation period, according to the most evident advantages of new techniques. Continuous cerebral perfusion through the right subclavian artery (RAACP) was introduced routinely in 2003. For RAACP to be performed, the right axillary artery is cannulated by inserting an $8 \mathrm{~F}$ cannula, and the perfusate is set at $12^{\circ} \mathrm{C}$ and applied between $14^{\circ} \mathrm{C}$ and $16^{\circ} \mathrm{C}$. The subclavian artery is perfused with oxygenated full blood at a flow of 1000 to $1500 \mathrm{~mL} / \mathrm{min}$ with a pressure of 30 to $40 \mathrm{~mm} \mathrm{Hg}$ or slightly above, also measured at the tip of the cannula. During RAACP, supra-aortic vessels are clamped at the origin. No specific neurologic monitoring was used during the procedure in this study group.
TABLE 1. Comparison of patients' demographics and preoperative clinical data

\begin{tabular}{lccc}
\hline & $\begin{array}{c}\text { Group 1 } \\
\text { (ascending aorta } \\
\text { crossclamped) } \\
(\mathbf{n}=\mathbf{1 9 1})\end{array}$ & $\begin{array}{c}\text { Group 2 } \\
\text { (ascending aorta } \\
\text { not crossclamped) } \\
(\mathbf{n}=\mathbf{7 4})\end{array}$ & $\begin{array}{c}\boldsymbol{P} \\
\text { value }\end{array}$ \\
\hline Age (y) & $61.3 \pm 11.9$ & $62 \pm 9.8$ & .408 \\
Male & $144(75.4 \%)$ & $50(67.6 \%)$ & .197 \\
History of myocardial & $9(4.7 \%)$ & $4(5.4 \%)$ & .815 \\
$\quad$ infarction & & & \\
History of smoking & $56(29.3 \%)$ & $15(20.3 \%)$ & .136 \\
Diabetes mellitus & $13(6.8 \%)$ & $2(2.7 \%)$ & .195 \\
Arterial hypertension & $117(61.3 \%)$ & $46(62.2 \%)$ & .892 \\
Hyperlipidemia & $24(12.6 \%)$ & $12(16.2 \%)$ & .436 \\
History of prior & $8(4.2 \%)$ & $7(9.5 \%)$ & .096 \\
$\quad$ cardiac surgery & & & \\
Aortic aneurysm & $81(42.4 \%)$ & $26(35.1 \%)$ & .279 \\
Marfan syndrome & $11(8.4 \%)$ & $1(2.4 \%)$ & .191 \\
Malperfusion syndrome & $66(34.6 \%)$ & $25(33.8 \%)$ & .906 \\
\hline
\end{tabular}

In patients from group 1, the ascending aorta was crossclamped and proximally transected during the cooling period. Selective antegrade blood cardioplegic solution was administered into the coronary ostia. Repair was performed by either supracoronary graft replacement with resuspension of the aortic valve or composite graft replacement of the aortic root, depending on the pathologic condition of the aortic valve and the sinuses (Table 2).

After proximal anastomosis, the distal anastomosis was performed bt the open technique along the principles described below for group 2 .

In group 2, the distal anastomosis was performed first after the anticipation of DHCA using the open technique. The patient was placed in the Trendelenburg position and the inner aortic lumen and origins of arch vessels were inspected. In all patients, the distal anastomosis was performed in the so-called "hemiarch" technique (Table 2). If the aortic arch or the descending thoracic aorta was dilated or completely destroyed by the dissection, aortic arch replacement with or without the elephant trunk technique was performed (Table 2). Then, after deairing of the prosthesis, the aortic arch, and supra-aortic vessels and the flushing of potential debris, the supracoronary graft was crossclamped and CPB was restarted. In the majority of patients, CPB was reinstituted through the side branch of the Vascutek Anteflow prosthesis (Vascutek Ltd, Inchinnan, Scotland). This allows the aorta to be perfused in an antegrade way. During the rewarming period, the proximal aortic anastomosis was accomplished along the principles described above for group 1 and the right axillary artery was reconstructed.

\section{Statistical Analysis}

Data are presented as mean values \pm their first standard deviation. The significance of difference between groups was assessed by the Student $t$ test, Mann-Whitney $U$ test, $\chi^{2}$, or the Fisher exact test, as appropriate. Data were analyzed with the StatView 4.1 statistical package (Abacus Concepts, Berkley, Calif). To compare and quantify the possible influence of all risk factors and the operative technique on the occurrence of cerebrovascular problems, we performed an ordinal regression analysis. As the dependent variable, we constructed a ranking in severity: mortality was considered as the most severe event, corresponding to a value of 5. Permanent stroke corresponded to 4, PRIND to 3, TIA to 2 , and TND to 1 . The absence of any cerebrovascular dysfunction corresponded to 0 , indicating the best outcome.

As possible influence factors, we included age, extracorporeal circulation time, and DHCA time as covariates and sex, history of smoking, diabetes, the presence of a malperfusion syndrome, redo surgery, and total arch 
TABLE 2. Comparison of patients' perioperative data

\begin{tabular}{|c|c|c|c|}
\hline & $\begin{array}{l}\text { Group } 1 \text { (ascending aorta } \\
\text { crossclamped) }(\mathrm{n}=191)\end{array}$ & $\begin{array}{c}\text { Group } 2 \text { (ascending aorta } \\
\text { not crossclamped) }(n=74)\end{array}$ & $P$ value \\
\hline Blood in pericardium & $63(33 \%)$ & $25(33.8 \%)$ & 901 \\
\hline Aortic cannulation & $9(4.7 \%)$ & $3(4.1 \%)$ & .817 \\
\hline Right axillary cannulation & $43(22.5 \%)$ & $24(32.4 \%)$ & .096 \\
\hline Femoral artery cannulation & $86(45 \%)$ & $23(31.1 \%)$ & .038 \\
\hline Iliac artery cannulation & $53(27.7 \%)$ & $24(32.4 \%)$ & .451 \\
\hline Composite graft replacement & $71(37.2 \%)$ & $8(10.8 \%)$ & $<.001$ \\
\hline Elephant trunk & $9(4.7 \%)$ & $8(10.8 \%)$ & .069 \\
\hline Including arch replacement & $1(0.5 \%)$ & $4(5.4 \%)$ & .009 \\
\hline ECC time (min) & $136.6 \pm 46.3$ & $133.6 \pm 42.5$ & .712 \\
\hline $\begin{array}{l}\text { Aortic/proximal aortic tube graft } \\
\text { crossclamping time (min) }\end{array}$ & $83.6 \pm 32.8$ & $70.2 \pm 31.4$ & $<.001$ \\
\hline DHCA time (min) & $22.9 \pm 8.7$ & $23.9 \pm 5.8$ & .135 \\
\hline RAACP & $43(22.5 \%)$ & $24(32.4 \%)$ & .096 \\
\hline Operation time & $238.3 \pm 66.0$ & $236.9 \pm 66.4$ & .740 \\
\hline
\end{tabular}

DHCA, Deep hypothermia and circulatory arrest; $E C C$, extracorporeal circulation; RAACP, continuous cerebral perfusion through the right subclavian artery.

replacement as factors. The overall goodness of fit was significant $(P=$ .000 ), the Nagelkerke pseudo $R^{2}=0.191$, indicating that about $19 \%$ of the variance can be explained by the model.

\section{RESULTS}

The preoperative patient characteristics and the perioperative data were similar (Table 1). Central nervous system malperfusion with all types of neurologic symptoms was observed in 27 patients in group 1, in which the ascending aorta was crossclamped $(14.1 \%)$, and 10 patients in group 2 , without clamping (13.5\%), which did not represent a significant difference between the two study groups $(P=$ not significant $[\mathrm{NS}]$ ).

Table 2 displays the comparison of patients' perioperative data.

TABLE 3. Comparison of patients' postoperative data and outcomes

\begin{tabular}{lccc}
\hline & $\begin{array}{c}\text { Group 1 } \\
\text { (ascending aorta } \\
\text { crossclamped) } \\
(\mathbf{n}=\mathbf{1 9 1})\end{array}$ & $\begin{array}{c}\text { Group 2 } \\
\text { (ascending aorta } \\
\text { not crossclamped) } \\
(\mathbf{n}=\mathbf{7 4})\end{array}$ & $\begin{array}{c}\boldsymbol{P} \\
\text { value }\end{array}$ \\
\hline In-hospital mortality & $29(15.2 \%)$ & $13(17.6 \%)$ & .633 \\
ICU stay (d) & $5.1 \pm 7.0$ & $3.73 \pm 3.2$ & .635 \\
IABP use & $4(2.1 \%)$ & $2(2.7 \%)$ & .765 \\
Revision for bleeding & $19(9.9 \%)$ & $4(5.4 \%)$ & .239 \\
Postoperative MI & $9(4.7 \%)$ & $9(12.2 \%)$ & .031 \\
Atrial fibrillation & $51(26.7 \%)$ & $14(18.9 \%)$ & .186 \\
Total CVIs & $43(22.5 \%)$ & $19(25.7 \%)$ & .585 \\
Transient neurologic & $25(13.1 \%)$ & $11(14.9 \%)$ & .705 \\
$\quad$ deficit (TIA, PRIND) & & & \\
Persistent neurologic & $18(9.4 \%)$ & $8(10.8 \%)$ & .734 \\
$\quad$ deficit & & & \\
TND & $26(13.6 \%)$ & $14(18.9 \%)$ & .279 \\
Length of hospital & $14.9 \pm 11.6$ & $12.6 \pm 8.5$ & .222 \\
$\quad$ stay (d) & & & \\
\hline
\end{tabular}

$\overline{C V I, \text { Cerebrovascular incident; } I A B P, \text { intra-aortic balloon pumping; } I C U \text {, intensive }}$ care unit; $M I$, myocardial infarction; PRIND, prolonged reversible ischemic neurologic deficit; TIA, transient ischemic attack; TND, temporary neurologic dysfunction.
There was no significant difference in in-hospital mortality between the two groups (Table 3). Six patients died in the operating room (mortality $2.1 \%$ in the clamped group and $2.7 \%$ in the nonclamped group; $P=\mathrm{NS}$ ). All operating room deaths were a result of "myocardial failure and not being able to come off CPB" in both groups. The clinical and neurologic outcomes did not show any significant difference other than postoperative myocardial infarction being more frequently observed in group 1 (Table 3). Overall intensive care unit stay tends to be longer in the group of patients in whom the aorta was clamped, without reaching statistical significance $(P=\mathrm{NS})$. All types of cerebrovascular incidents are reported for both groups with $22.5 \%$ in the clamped group compared with $25.7 \%$ in the nonclamped group. Cerebrovascular events were labeled as persistent (neurologic symptoms $>72$ hours) and transient (neurologic symptoms $<72$ hours). Also, no difference was found in the repartition of persistent and transient neurologic symptoms within both groups.

Looking at the data of the ordinal regression analysis, we found that neurologic outcome in our series was mainly affected by the presence of malperfusion, age at the time of operation, extracorporeal circulation time, and duration of DHCA (Table 4).

\section{DISCUSSION}

Today a majority of surgeons perform the distal anastomosis for repair of AADA in the so-called open technique at the level of the proximal aortic arch..$^{3,7,9,10}$ The advantage of DHCA and the open technique is that the inner aortic lumen can be visualized for detection of longitudinal intimal tear in the aortic arch, including the origin of the aortic arch vessels. Thus a more delicate reconstruction of the dissected aortic layers can be achieved with biologic glue, and we believe that suturing can be performed more easily without the clamp on the aorta. ${ }^{1,5}$ 
TABLE 4. Ordinal regression analysis

\begin{tabular}{lccc}
\hline & Estimator & Significance & 95\% CI \\
\hline Age at the time of surgery & 0.037 & .005 & $.011-.062$ \\
ECC time & 0.008 & .010 & $.002-.014$ \\
DHCA time & 0.038 & .025 & $.005-.014$ \\
Gender & -0.107 & .717 & $-.685-.471$ \\
History of smoking & 0.082 & .783 & $-.502-.665$ \\
Diabetes mellitus & 0.275 & .614 & $-.794-1.344$ \\
Malperfusion syndrome & -0.926 & .000 & $-1.439-.41$ \\
Redo surgery & 0.358 & .547 & $-.807-1.522$ \\
Total arch replacement & 1.885 & .125 & $-.523-4.293$ \\
Axillary perfusion & -1.627 & .059 & $-3.317-.063$ \\
Composite graft & 0.460 & .154 & $-.173-1.094$ \\
\hline$C I$, Confidence interval; $E C C$, extracorporeal circulation; $D H C A$, deep hypothermic \\
circulatory arrest.
\end{tabular}

However, surgeons who perform the distal anastomosis by the open technique have not yet come to a consensus about the following question: Should the ascending aorta be clamped during the cooling phase before DHCA or should this maneuver be avoided? To our knowledge, this question has not yet been fully elucidated in the literature.

The potential advantages of crossclamping the ascending aorta during of the cooling phase may be as follows: (1) to prevent left ventricular distention, especially in patients with significant aortic insufficiency; (2) to allow more rapid establishment of cardiac arrest by direct application of cardioplegic solution through the coronary ostia; (3) to control bleeding in case of aortic rupture; and (4) to shorten operative time when a more complex procedure on the aortic root is required (eg, aortic valve reimplantation after David or composite graft) instead of the more simple supracoronary aortic replacement.

On the other hand, potential risks of crossclamping the ascending aorta during cooling may be as follows: (1) clamp injuries of the fragile ascending aorta; (2) mobilization of the clot into the lumen and greater vessels, which may lead to cerebral or peripheral embolization; (3) false lumen perfusion against the aortic crossclamp with consecutive distension of the false channel; (4) brachiocephalic malperfusion owing to an aortic intimal flap with a consequent increase in perioperative stroke risk; and (5) worsening extension of dissection.

In the present study, we were not able to observe any significant difference in operating room or in-hospital mortality rates between the two study groups. Including all 275 patients who were consecutively operated on during the observational period starting in 1994, the overall mortality was $16.4 \%(45 / 275)$. Most recently, the mortality rate decreased to $8 \%$ to $9 \%$ in our study. Our study results support prior observations that despite all of the surgical advances, AADAs still remain a major challenge, with operative mortality rates of $15 \%$ to $28 \%$ and stroke rates of $2 \%$ to $15 \%$. $^{4,5,11-19}$
Aortic crossclamping might be the cause of permanent or transient neurologic dysfunction as a consequence of cerebral malperfusion and/or embolization. In the literature, it has been widely discussed that the aortic intimal flap may produce brachiocephalic malperfusion with a consequent increase in perioperative stroke risk. ${ }^{20-25}$ However, our data could not confirm any negative effect of crossclamping on neurologic outcome. The left radial arterial pressure, which is routinely used for blood pressure monitoring in case of axillary cannulation on the right side, may not be reliable to follow malperfusion since it might be unaffected. ${ }^{20}$ The detection of brachiocephalic malperfusion during operative repair of AADA has been described with transesophageal echocardiography, transcranial Doppler, transcutaneous ultrasound carotid imaging, electroencephalogram, and regional cerebral oximetry. ${ }^{20}$ In all our cases, we used transesophageal echocardiography routinely, but we did not detect perioperative malperfusion in any of the cases.

Van Arsdell, David, and Butany ${ }^{26}$ reported in their autopsy series of AADA that patients who did not undergo surgery often had only one entry and reentry tear compared with patients operated on with aortic crossclamping, who generally had multiple tears. The authors speculated that mechanical trauma applied to the aortic wall during crossclamping was responsible for this finding. Zierer and associates ${ }^{27}$ believed that a mechanical trauma like aortic crossclamping may increase the risk of focal cerebral injuries owing to the dispersion of intra-aortic atheromatous debris. However, we believe that atheromatous emboli should be of less concern for aortic crossclamping with DHCA, because the crossclamp is released after circulatory arrest and the ascending aorta is thereafter replaced. However, aortic crossclamping may theoretically squeeze the clot into the lumen and greater vessels and may cause thromboemboli. Nevertheless, we did not observe any difference in neurologic complications between the two study groups.

Several definitions of neurologic outcome can be found in the literature. However, comparing our results with the data published in other studies shows that the incidence of transient and persistent neurologic symptoms is very similar. ${ }^{27}$

We introduced routine axillary artery cannulation instead of perfusion through the femoral artery in 2003 to avoid potential malperfusion and atheroembolic complications associated with retrograde perfusion in AADAs. ${ }^{20,28-30}$ In the current study interval, femoral artery cannulation was more frequent in group I only because of historical reasons, whereas CPB times and duration of DHCA were similar. In group 1, the rate of composite graft replacement is higher. Those patients which frequently required more root reconstruction with composite graft replacement since they had significant aortic regurgitation more often.

Looking at the results from the ordinal regression analysis, we can confirm that cerebrovascular incidents are mainly caused in the presence of a malperfusion syndrome, 
increased age, and time of operation. These findings are not unexpected, but in the most recent period, subclavian artery cannulation has led to a significantly lower reduction of cerebrovascular complications, less malperfusion, and improved early outcome. ${ }^{8}$

\section{LIMITATIONS}

This is a retrospective observational study. Some important patient characteristics such as history of stroke, history of carotid artery occlusion, alcoholism, renal failure, chronic obstructive pulmonary disease, and ejection fraction could not be included in the analysis because of missing data.

Considering the limitations of the study and theoretical risks of aortic crossclamping, we prefer to make a cautious conclusion: Aortic crossclamping during cooling before DHCA probably does not affect the clinical outcome. Inasmuch as there is no difference in early clinical outcomes, both techniques may be used. Selection may occur on a case-by-case basis, weighing the potential risks and benefits of aortic crossclamping, considering the severity of aortic regurgitation, left ventricular distention, and the pulmonary artery pressure.

We thank Brigitta Gahl, dipl Math, for her help in statistical analysis.

\section{References}

1. Svensson LG, Crawford ES. Techniques for dissection involving the proximal aorta. In: Svensson LG, Crawford ES, eds. Cardiovascular and vascular disease of the aorta. Philadelphia: WB Saunders Company; 1997. p. 296-335.

2. Ehrlich MP, Ergin MA, McCullough JN, Lansman SL, Galla JD, Bodian CA, et al. Results of immediate surgical treatment of all acute type A dissections. Circulation. 2000;102(Suppl):III248-52.

3. Elefteriades JA. What operation for acute type A dissection? J Thorac Cardiovasc Surg. 2002;123:201-3.

4. Lai DT, Miller DC, Mitchell RS, Oyer PE, Moore KA, Robbins RC, et al. Acute type A aortic dissection complicated by aortic regurgitation: composite valve graft versus separate valve graft versus conservative valve repair. J Thorac Cardiovasc Surg. 2003;126:1978-86.

5. David TE, Armstrong S, Ivanov J, Barnard S. Surgery for acute type A aortic dissection. Ann Thorac Surg. 1999;67:1999-2001.

6. Westaby S, Saito S, Katsumata T. Acute type A dissection: conservative methods provide consistently low mortality. Ann Thorac Surg. 2002;73:707-13.

7. Danner CB, Natour E, Horst M. Comparison of operative techniques in acute type A dissection performing the distal anastomosis. J Card Surg. 2007;22:105-10.

8. Immer FF, Grobéty V, Lauten A, Carrel TP. Does malperfusion syndrome affect early and mid-term outcome in patients suffering from acute type A aortic dissection? Interact Cardiovasc Thorac Surg. 2006;5:187-90.

9. Griepp RB, Stinson EB, Hollingsworth JF, Buehler D. Prosthetic replacement of the aortic arch. J Thorac Cardiovasc Surg. 1975;70:1051-63.

10. Fusco DS, Shaw RK, Tranquilli M, Kopf GS, Elefteriades JA. Femoral cannulation is safe for type A dissection repair. Ann Thorac Surg. 2004;78:1285-9.
11. Kallenbach K, Oelze T, Salcher R, Hagl C, Karck M, Leyh RG, et al. Evolving strategies for treatment of acute aortic dissection type A. Circulation. 2004; 110(11 Suppl 1):II243-9.

12. Sinatra R, Melina G, Pulitani I, Fiorani B, Ruvolo G, Marino B. Emergency operation for acute type A aortic dissection: neurologic complications and early mortality. Ann Thorac Surg. 2001;71:33-8.

13. Moon MR, Sundt TM 3rd, Pasque MK, Barner HB, Huddleston CB, Damiano RJ Jr, et al. Does the extent of proximal or distal resection influence outcome for type A dissections? Ann Thorac Surg. 2001;71:1244-9.

14. Moon MR, Miller DC. Aortic arch replacement for dissection. Op Tech Thorac Cardiovasc Surg. 1999;4:33-57.

15. Moon MR, Sundt TM 3rd. Aortic arch aneurysms. Coron Artery Dis. 2002;13: 85-92.

16. Goldstein LJ, Davies RR, Rizzo JA, Davila JJ, Cooperberg MR, Shaw RK, et al. Stroke in surgery of the thoracic aorta: incidence, impact, etiology, and prevention. J Thorac Cardiovasc Surg. 2001;122:935-45.

17. Bachet J, Guiltmet D. Current treatment of acute dissections of the ascending aorta. Arch Mal Coeur Vaiss. 1997;90:1769-80.

18. Ehrlich MP, Schillinger M, Grabenwöger M, Kocher A, Tschernko EM, Simon P, et al. Predictors of adverse outcome and transient neurological dysfunction following surgical treatment of acute type A dissections. Circulation. 2003; 108(Suppl 1):II318-23.

19. Hagan PG, Nienaber CA, Isselbacher EM, Bruckman D, Karavite DJ, Russman PL, et al. The International Registry of Acute Aortic Dissection (IRAD): new insights into an old disease. JAMA. 2000;283:897-903.

20. Jakob H, Tsagakis K, Szabo A, Wiese I, Thielmann M, Herold U. Rapid and safe direct cannulation of the true lumen of the ascending aorta in acute type A aortic dissection. J Thorac Cardiovasc Surg. 2007;134:244-5.

21. Appoo JJ, Augoustides JG, Pochettino A, Savino JS, McGarvey ML, Cowie DC, et al. Perioperative outcome in adults undergoing deep hypothermic circulatory arrest with retrograde cerebral perfusion in proximal aortic arch repair: evaluation of protocol-based care. J Cardiothorac Vasc Anesth. 2006;20:3-7.

22. Bavaria JE, Brinster DR, Gorman RC, Woo YJ, Gleason T, Pochettino A, et al. Advances in the treatment of acute type A dissection: an integrated approach. Ann Thorac Surg. 2002;74:S1848-52.

23. Neustein SM, Lansman SL, Qunitana CS, Suriani R, Ergin A, Griepp RB. Transesophageal Doppler echocardiographic monitoring for malperfusion during aortic dissection repair. Ann Thorac Surg. 1993;56:358-61.

24. Fukada J, Morishita K, Kawaharada N, Yamauchi A, Hasegawa T, Satsu T, et al. Isolated cerebral perfusion for intraoperative cerebral malperfusion in type A aortic dissection. Ann Thorac Surg. 2003;75:266-8.

25. Sakaguchi G, Komiya T, Tamura N, Obata S, Masuyama S, Kimura C, et al. Cerebral malperfusion in acute type A dissection: direct innominate artery cannulation. J Thorac Cardiovasc Surg. 2005;129:1190-1.

26. Van Arsdell GS, David TE, Butany J. Autopsies in acute type A dissection. Surgical implications. Circulation. 1998;98(19 Suppl):II299-302; discussion II302-4.

27. Zierer A, Moon MR, Melby SJ, Moazami N, Lawton JS, Kouchoukos NT, et al. Impact of perfusion strategy on neurologic recovery in acute type A dissection. Ann Thorac Surg. 2007;83:2122-8; discussion 2128-9.

28. Svensson LG, Blackstone EH, Rajeswaran J, Sabik JF 3rd, Lytle BW, Gonzalez-Stawinski G, et al. Does the arterial cannulation site for circulatory arrest influence stroke risk? Ann Thorac Surg. 2004;78:1274-8; discussion 1274-84.

29. Strauch T, Spielvogel D, Lauten A. Axillary artery cannulation: routine use in ascending aorta and aortic arch replacement. Ann Thorac Surg. 2004;78: 103-8.

30. Reuthebuch O, Schurr U, Hellermann J, Prêtre R, Künzli A, Lachat M, et al. Advantages of subclavian artery perfusion for repair of acute type A dissection. Eur J Cardiothorac Surg. 2004;26:592-8. 